\title{
Process-Oriented Order Processing -A New Method for Business Process Re- engineering
}

\author{
Prof. Dr.-Ing. Dr. h. c. Dipl.-Wirt. Ing. W. Eversheim, \\ Dipl.-Ing. Th. Heuser \\ Laboratory for Machine Tools and Production Engineering, \\ Steinbachstr. 53 B, 52056 Aachen, Germany, phone: ++49/241/80- \\ 7404, fax: ++49/241/88 88-293, e-mail: heu@wzl-ps1.wzl.rwth- \\ aachen.de
}

\begin{abstract}
Todays world is continuously changing. High quality and flexibility as well as low cost are the main objectives in production. Therefore it is necessary to have a process-oriented organisation of customer-led order processing from order clarification to shipping. In the following a model will be described to analyse and depict business processes as carried out in a company, to identify organisational problems, and to simulate lead time optimisation. In addition this model can be used to evaluate business processes according to the cause of cost under consideration of resource consumption.
\end{abstract}

Keywords

Process-oriented order processing, business process reengineering, activity based costing, organisation

\section{INTRODUCTION}

During the processing of customer orders, large problems appear especially in small and midsized companies due to the current economic situation. Despite the decreasing order volume, an increasing volume of work must be accomplished because of a growing number of special requests at lower prices for the product. Short lead-times and the keeping of guaranteed delivery dates based on good procedure organisation are the parameters which are decisive for competitiveness, whose optimisation for companies was until now an only unsatisfactorily 
solved problem. Even currently, many companies neglect an adjustment of their organization especially in respect to the production tasks which are becoming ever more complex (Eversheim, 1994-a). Through an organisation strongly characterised by job segmentation in manufacturing companies, the previously sensible functional-oriented structures in manufacturing have solidified themselves even in the ever growing area of administration (Eversheim, 1993-a).

Rationalisation measures, for instance, to influence lead-time and costs, have been increasingly taken over by the direct company departments manufacturing and assembly in the last few years. The rationalisation potential in the indirect company departments has not been taken fully into consideration. Companies indirect departments have a central meaning on efficiency of order processing. Especially there, however, the lead-times consist of 60$80 \%$ of total customer lead-time. $75 \%$ of the employees process information and not material. This leads to overhead costs which are about $50 \%$ of total cost [Groß, 1992; Eversheim, 1992; Traenckner, 1990). One of the main reasons is insufficient transparency. Hence, many important questions which occur in daily business remain unanswered (Figure 1) (Eversheim, 1994-b).

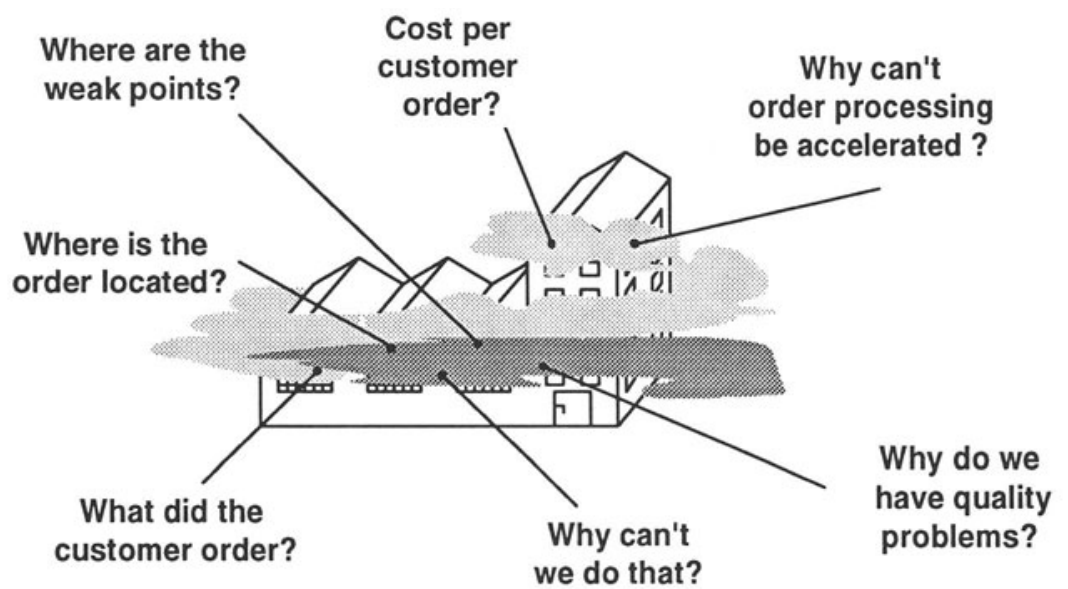

Figure 1 Insufficient transparency in order processing

Only through a total view of the order processing, aimed at realising an interconnecting, universal process, can single solutions be replaced by solutions which are department-wide with suitable requirements and can the processing of orders be placed at the center of the examination (Figure 2) (Striening, 1988; Gaitanides, 1983).

Within the framework of the organisational design, the perspective of the manufacturing costs of the resource consumption is linked to the order completion. This makes possible a differentiated view of resource consumption since it is related to the order measurably and manipulatively. The activities usually booked and hidden in the so-called overhead costs can now be analysed and examined in order to realise goals such as lean production. 


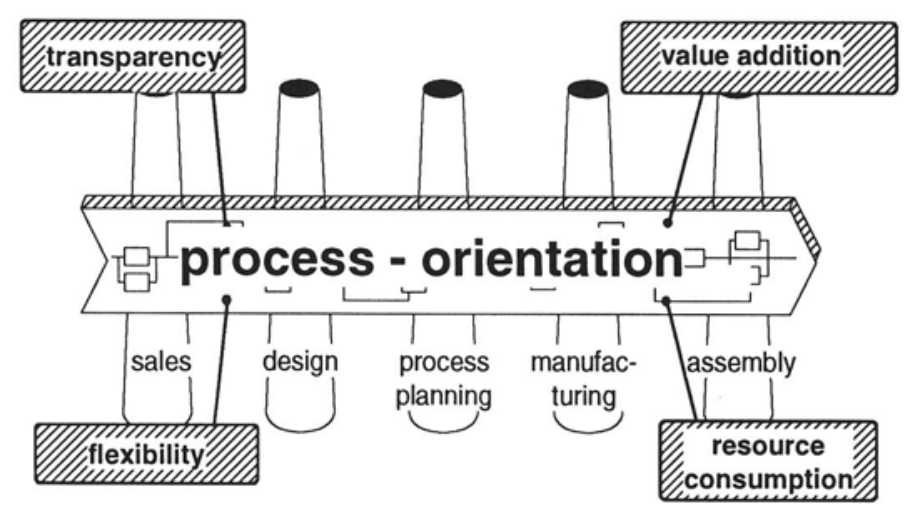

Figure 2 Process-Orientation-Precondition for improved competitiveness

\section{FUNDAMENTALS OF PROCESS-ORIENTATION IN ORDER PROCESSING}

Considering these problems, researchers of the Laboratory for Machine Tools (WZL) at the Aachen University of Technology developed a model of a process-oriented organisation of order processing. This model takes all necessary aspects into consideration, such as methods to implement customer-oriented organisation structures and methods for order scheduling and control. The model provides a method for busines process re-engineering.

The simultaneous optimisation of lead-time, costs and quality is mostly linked with a conflict of objectives since, for example, a minimisation of the lead-time carries with it high costs and possible sacrifices in quality. The application of the model process-oriented order processing allows to optimise the above mentioned objectives either individually or in the overall context (Figure 3 ).

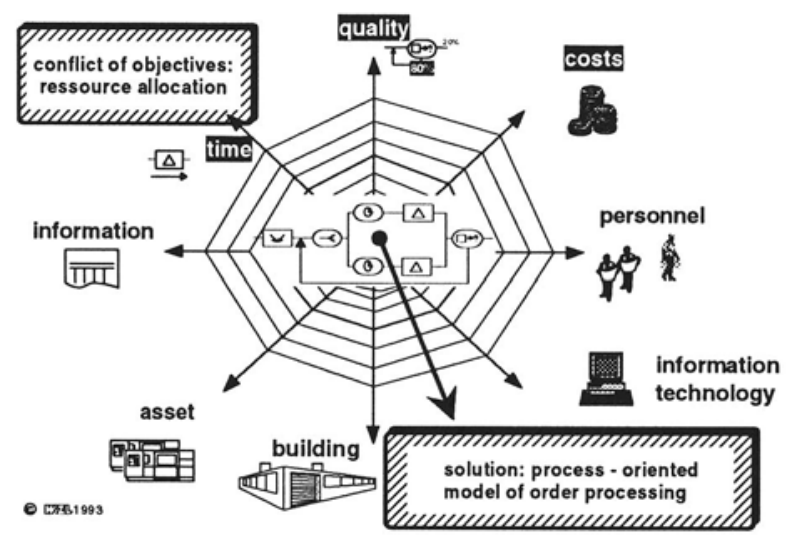

Figure 3 Integrated optimisation of time, quality and costs 
A standardised modelling language was developed to depict the various mechanics of business order processing. Based on the modelling language, it is possible to reorganise and evaluate order processing. To make the evaluation practicable each element of the process is linked with resources, such as personnel, capital, asset etc. In this manner it can be evaluated in how far improvement measures can help in achieving the objectives time, costs and quality. Moreover it is possible to have a look at the changes e. g. in time and costs if you only optimise quality.

For the overall depiction of order processing, 14 basic "process elements" were developed (Figure 4). These elements compose the modelling language for order processing depiction from order placement to shipping. They are classified into direct and indirect element types. Indirect elements such as linkage, decide, and communicate etc., describe activities with an indirekt contribution to value addition of order processing. Direct process elements describe the activities causing a direct accretion to an order, such as designing, process planning, or manufacturing.

The method of business process re-engineering provides a general approach to apply the elements to their use in practice. It consists of the steps: building up the process-oriented model of order processing, calculate average lead-times or costs, identify weaknesses in order processing, and evaluate measures to be taken.

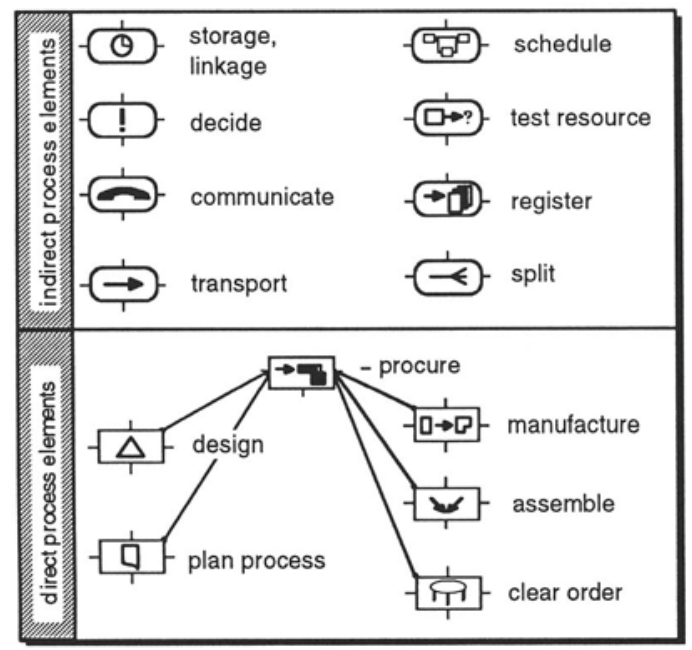

Figure 4 Elements of modelling language

For the application of the modelling language the elements are connected according to the sequence the order is processed. For that purpose, the elements provide one inlet on the left side and two resectively three outlets on the top, bottom, and the right side. The outlet to the right side represents the normal outlet for a trouble-free executed process. The bottom line shows the outlet for an interrupted process in case the alternative processes are known (e.g. test completeness of information during design process $\Rightarrow>$ procure lacking information from sales department). An order flows through the top outlet of an element when a decision about 
the following processes can not be made. The complete model is depicted in the so-called business process sequence plan.

\section{APPLICATION OF THE MODEL}

The implementation of analysis and reorganisation begins with the creation of a team of employees since order processing will be recorded based on interviews. The operative employees who have experience in order processing will be questioned. The analysis extends from offer and order processing in sales to product delivery through shipment or bringing into operational use for the customer. Employees from respective departments report in what sequence the incoming orders are processed (Figure 5). The analysis team presents the processes and their description in the business process sequence plan (BPSP). After completion of the BPSP, the depiction must be verified by the process owner (the employee who carries out the respective processes). Then, the corrections will be worked into the procedure depiction. This cycle will be implemented until the BPSP correctly reflects the procedures in the company (Eversheim, 1993-b).

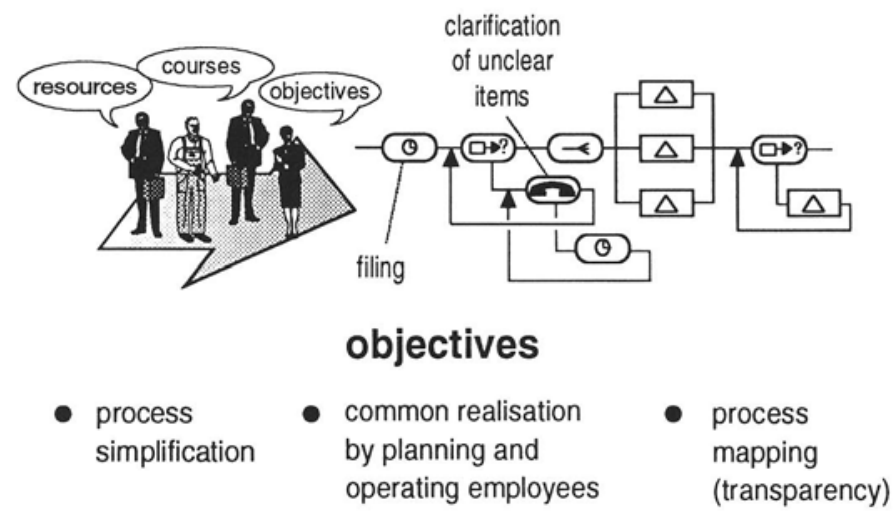

Figure 5 Complexity reduction is based on process analysis (Eversheim, 1994-c)

The quantification phase follows the creation of the BPSP. For this, two kinds of data per process must be incorporated in the throughput reorganisation explained. First of all, the average length of time for the implementation of a process is to be determined, and second, the probability recorded with which an order will leave a process through the respective exit.

It is important that the employees who carry out each process are asked about the average lead-times per process. These values have proved themselves to be exact enough in practice.Processing time on the scale of minutes in a total processing time of several months, or conversion probability values after the decimal point supply in this case no extra information and overtax the employees. The incorporated times serve only the order 
processing time calculation and do not allow any conclusions about the capacity utilisation of an employee.

The result of the analysis steps "Inclusion and Quantification of Order Completion Processes" will be depicted graphically. As an example, the BPSP shown in Figure 6 is presented which indicates a section of the total process chain. In this case the procedures for the processing of individual components of an order is depicted.

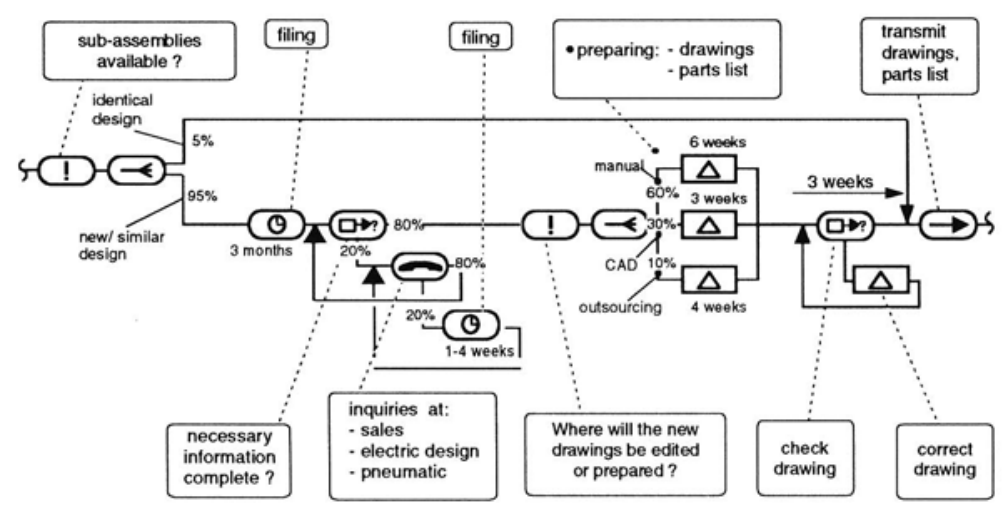

Figure 6 Business process sequence plan BPSP (example)

To support the approach an IT-Tool was developed. By applying the tool, the most important information about the processes carried out are recorded quickly and simply (Figure 7). To make the software accessible for industrial companies, as well, the system was lead to market maturity within the framework of a development cooperation between WZL, a software firm and 8 industrial companies. The analysis tool is operative on IBM compatible PCs under WINDOWS.

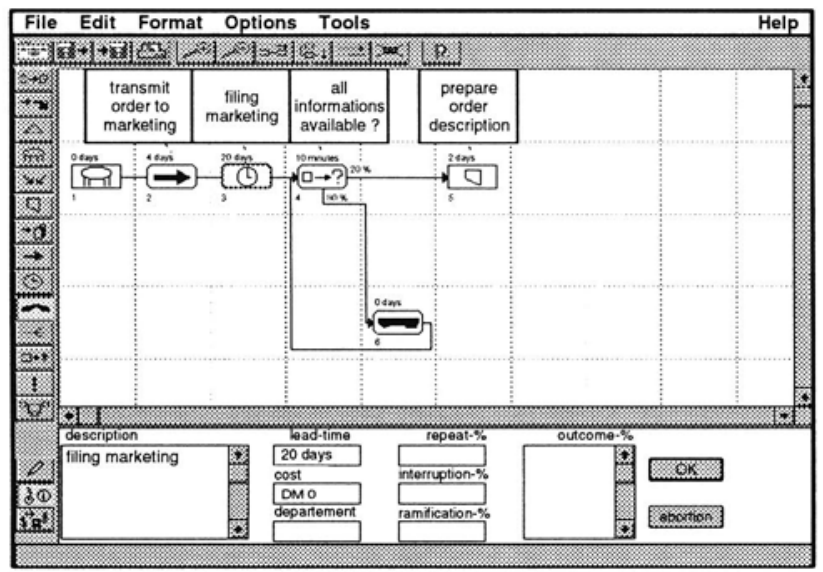

Figure 7 Proplan-IT-Tool for business process re-engineering 
It is especially meaningful that the tools to be used, such as an EDP support, be simple and fast to employ, so that the employees are not held up from their daily tasks too long while carrying out the improvement process. Furthermore, the continual care and use of the BPSP serves as a continuous control of the organisation improvements made so far. The application of PROPLAN reduces the total efforts of business re-engineering up to $75 \%$.

The BPSP contains all necessary information to calculate the average lead-time of an order regarding the considered process chain. For this, specially developed formulas are used. In these formulas, it is taken into consideration that time consumption based in feedback loops (e.g. inquiries based on missing information) is also based on the fact that some orders can run through it several times (Müller, 1992).

After the lead-time calculation regarding the current situation, the actual weakness analysis will be carried out. The weaknesses in order processing can be localised using various criteria. For example, processes with long lead-times in relation to the total lead-time will be examined. They could be value adding processes or processes which, for example, are characterised by idle times.

\section{ACTIVITY BASED COSTING}

In addition to a reduction of lead-time it is also important to reduce the costs. Efforts for costs reduction require a differentiated product and process cost consideration in all company departments. Especially in the up to now often neglected indirect company departments cost transparency is necessary. A charging of rendering services according to the cause of costs leads to an improved control of overhead costs. To share out overhead cost in a correct way, the WZL developed a method for a differentiated cost evaluation (Figure 8). A linkage of business processes and resource consumption is the basis of this method.

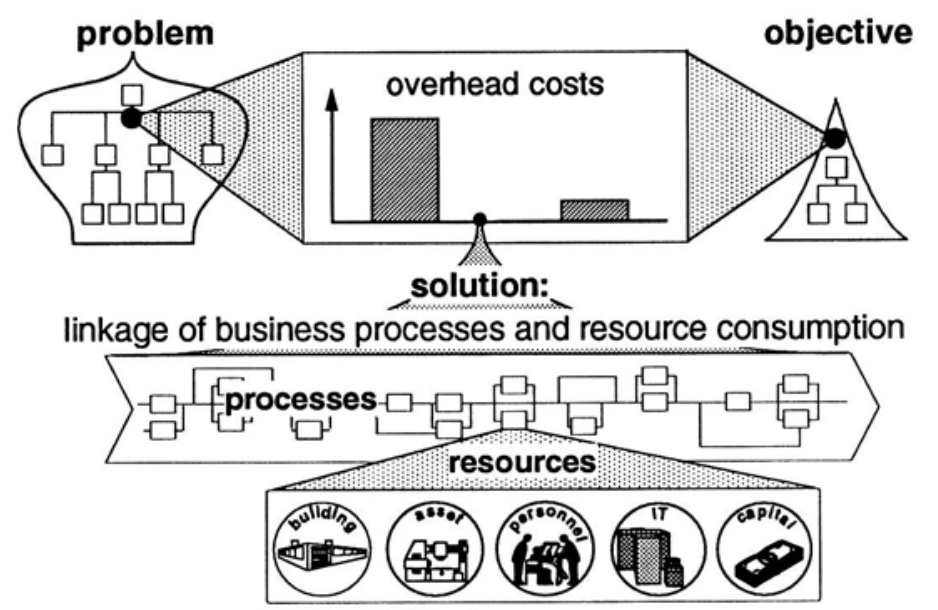

Figure 8 Overhead cost reduction 
The resource consumption is described by the resource model (Figure 9). This model serves to evaluate business process comprehensively concerning the objectives lead-time, costs and quality. Therefore company resources personnel, information technology, asset, building, capital, material, information and time will be differentiated fundamentally.

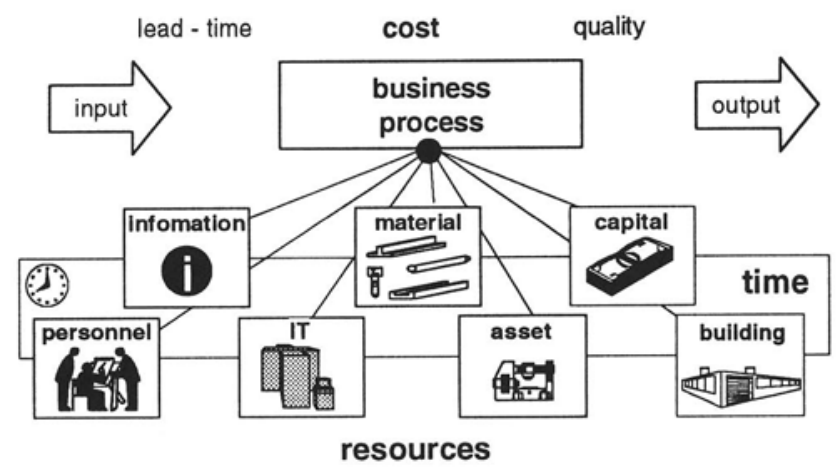

Figure 9 Elements of the resource model

The resource model has in view to describe the depreciation of examined business processes dependent on cost drivers (Figure 10). The depreciation of a business process will be determined by a relation between cost driver and resource consumption.

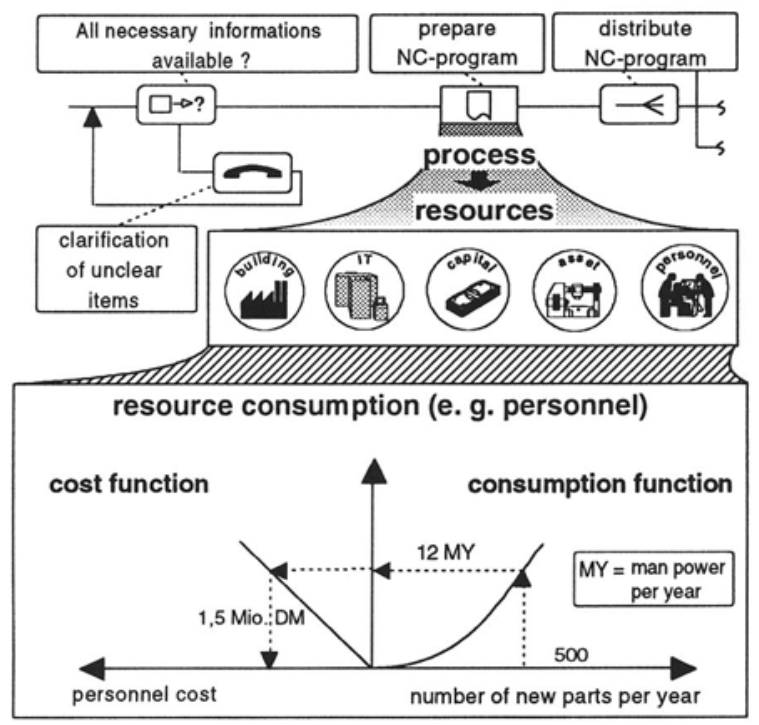

Figure 10 Evaluation according to the cause of costs 
In general, cost drivers are technological and organisational oriented parameters (e.g. number of orders to be processed, number of new self-produced articles per year). With the specific cost rate the consumption function of a company resource is linked to a cost function (Eversheim, 1993-c)

The connection between these two functions represents the resource model. The application of the resource model integrates engineering and financial tasks (Schuh, 1988). Proved fields of application are optimisation of resource consumption during order processing, calculation of products according to the cause of costs, evaluation of variants, and the design of manufacturing and assembly lay-outs.

\section{APPLICATION IN SME'S}

The successes which WZL has had with the employment of business process re-engineering in industry show the meaningfulness of offering help toward selfhelp. The wide range of branches runs from special machine tool manufacture to series and large-series manufacture (Figure 11). The potential that was realised, for example through the reduction of lead-time, lies between $20 \%-50 \%$ of total lead-time.

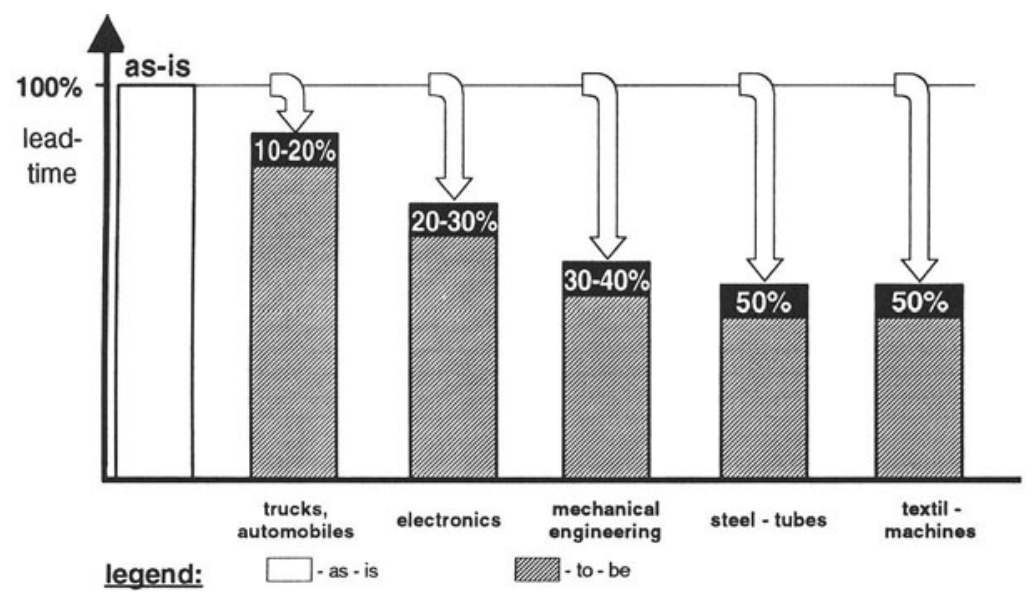

Figure 11 Results of business process re-engineering

By implementing the methods the following was achieved:

- transparency in the current sequences;

- exact localisation of the main weaknesses;

- concrete improvement measures;

- evaluation of all measures relating to their effect on shortening total lead-time time or cost reduction and

- setting up project priorities to realise the measures. 
The experience gathered in practice shows that the method and the tool were well accepted by operative employees in direct and especially in indirect company departments. Due to the transparency produced, the preparedness for fundamental change in the company has drastictly increased.

\section{SUMMARY AND OUTLOOK}

The employment of the method leads to transparency of processes, resource consumption and costs. The accurate evaluation of reorganisation measures is made possible. An IT-Tool was developed, to reduce the expenditure of process analysis distinctly.

Following a project for continuous improvement with WZL some companies adopted the method of process analysis for continuous improvement. The continuous employment and improvement put up here an essential contribution to overcome the "operational blindness" and the increase of competitiveness particularly in today's difficult economic situation.

BPSP's which were constructed for the current and target condition are able to be used extensively after a project since they represent the company's know-how in broad range. They represent, for instance, a suitable work foundation for the implementation planning and control. That means the continuous IT-supported documentation of process change is a constant measurement for the realisation of the reorganisation measures (Figure 12). The documented procedures, such as WZL's experience has shown, furthermore can be used within the framework of a certification according to ISO 9001-4.

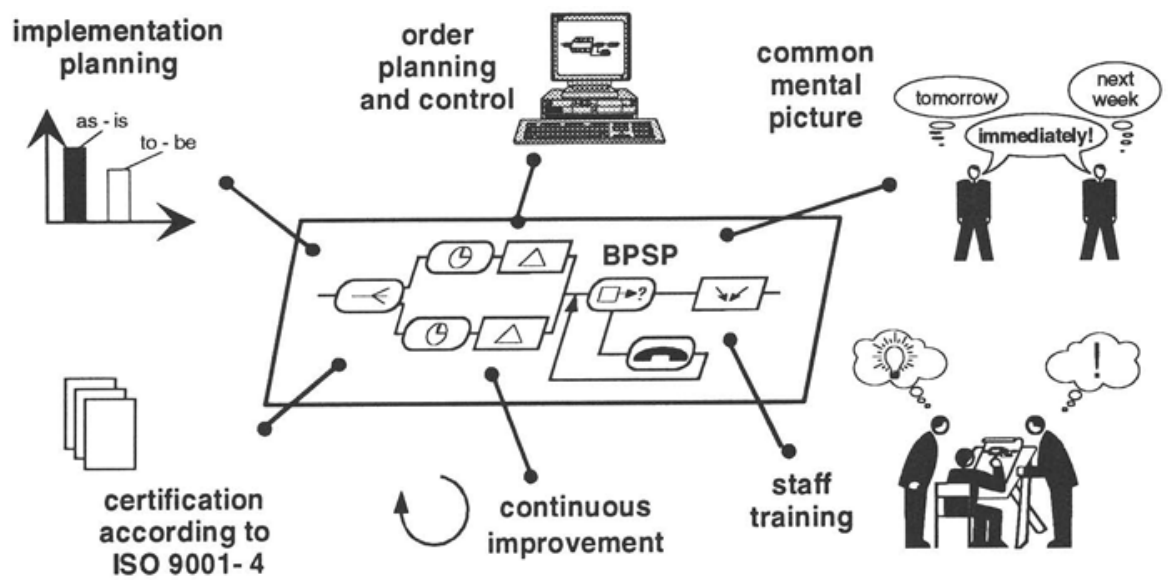

BPSP = business process sequence plan

Figure 12 Further fields of BPSP application

Further areas of application can be found in employee training. The transparent and easy-tounderstand presentation of the company procedures simplifies training especially in view of new employees and leads to better understanding on all sides. A common mental picture for 
all employees is an important requirement for "mental fitness" for the consistent realisation of process organisation in a company.

\section{REFERENCES}

Eversheim, W.; König, W.; Pfeifer, T.; Weck, M. (1994-a) Manufacturing Excellence. The copetitive edge, Chapman \& Hall, London

Eversheim, W.; Krumm, St.; Heuser, Th. (1994-b) Ablauf- und Kostentransparenz; CIM Management 10, Nr. 1, S. 57-59

Eversheim, W.; Heuser, Th.; Kümper, R. (1994-c) Verringerung und Beherrschung der Komplexität stärkt die Wettbewerbsfähigkeit; Referat zum Münchner Kolloquium; Hrsg.: Milberg, Springer Verlag, Berlin

Eversheim, W.; Krumm, St., Heuser, Th.; Müller, Th. (1993-a) Process - Oriented Order Pocessing. A New Method to Meet Customer Demands, In: Annals of CIRP, Vol. 42/1, S. 569-571

Eversheim, W.; Krumm, St.; Heuser, Th., Popp, W. (1993-b) Prozeßorientierte Reorganisation der Auftragsabwicklung; VDI-Z 135, Nr. 11/12, S. 119-122

Eversheim, W.; Krumm, St.; Heuser, Th. (1993-c) Prozeßorientierte Auftragsabwicklung; VDI-Z 135, Nr. 10, S. 48-51

Eversheim, W.; Müller, St.; Heuser, Th. (1992) "Schlanke" Informationsflüsse schaffen; VDI-Z 134, Nr. 11, S. 66-69

Gaitanides, M. (1983) Prozeßorganisation, Entwicklung, Ansätze und Programme prozeßorientierter Organisationsgestaltung. Verlag Franz Vahlen, München 1983

Groß, M.; Müller, St.; Heuser, Th. (1992) Schlank und rank; Zeitschrift Fabrik 2000, Nr. 2, S. 21-25

Müller, St. (1992) Entwicklung einer Methode zur prozeßorientierten Reorganisation der technischen Auftragsabwicklung komplexer Produkte. Dissertation RWTH Aachen

Schuh, G. (1988) Gestaltung und Bewertung von Produktvarianten, Dissertation RWTH Aachen

Striening, H.-D. (1988) Prozeßmanagement: Versuch eines integrierten Konzeptes situationsadäquater Gestaltung von Verwaltungsprozessen in einem multinationalen Unternehmen. Dissertation, Universität Kaiserslautern

Traenckner, J.-H.(1990) Entwicklung eines prozeß- und elementorientierten Modells zur Analyse und Gestaltung der technischen Auftragsabwicklung von komplexen Produkten; Dissertation, RWTH Aachen

\section{BIOGRAPHY}

Prof. Dr.-Ing. Dr. h.c. Dipl.-Wirt. Ing. Walter Eversheim born in 1937, study of mechanical and industrial engineering, $\mathrm{PhD}$ in 1965 at Aachen University of Technology. From 1969 to 1973 leading functions in several industrial companies. Since 1973 director of Laboratory for Machine Tools and Production Engineering at Aachen University of Technology, holder (head) of the chair for Production 
Engineering. Since 1980 director of the Fraunhofer-Institute for Production Technology in Aachen. Since 1989 director of the Institute for Technology-Management at the University of Saint Gallen, Switzerland. Since 1990 director of Research-Institute for Rationalisation, Aachen University of Technology. In 1992, award of Dr. techinicae honoris causa from University of Trondheim, Norway.

Dipl.-Ing. Thomas Heuser, born in 1963, study of mechanical engineering at Aachen University of Technology. Since 1991 scientific employee at Laboratory for Machine Tools and Production Engineering at Aachen University of Technology. Since 1994 head of the section "assembly". Field of activity: business-process re-engineering. 